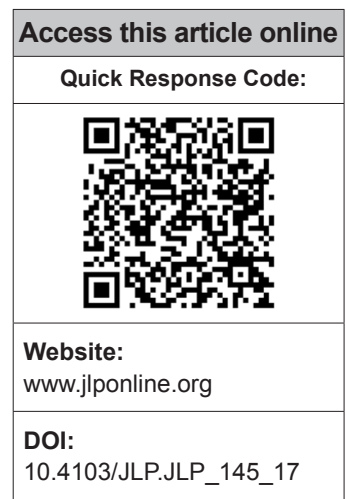

Department of Microbiology, GSL Medical College, Rajahmundry, Andhra Pradesh, India

Address for correspondence:

Dr. T. Jaya Chandra,

Department of

Microbiology, GSL Medical College, Rajahmundry, Andhra Pradesh, India. E-mail: chanduthegreat 2014@gmail.com

Submission: 25-09-2017 Accepted: 14-11-2017

\title{
One-sample two-smear versus two-sample two-smear approach for the diagnosis of pulmonary tuberculosis
}

\author{
T. Jaya Chandra
}

\section{Abstract:}

BACKGROUND: To evaluate the efficacy of one-sputum sample two-smear approach for the diagnosis of pulmonary tuberculosis (PT).

MATERIALS AND METHODS: Data from January 2012 to December 2015 were analyzed to find (1) number of smear positives (SPs) by spot (S) sample with one and two smears; (2) number of SPs by morning (M) sample with one and two smears; and (iii) number of SPs by two samples with two smears, that is, same-day $\left(\mathrm{SS}_{2}\right)$ and spot morning (SM) approaches. The Chi-square test was used to evaluate the statistical difference in SP cases.

RESULTS: With one-sample two-smear approach, the smear positivity (SPT) was $87 \%$ and $87.5 \%$, for $\mathrm{S}$ and $\mathrm{M}$ samples, respectively, for Ziehl-Neelsen (ZN) staining; whereas, SPT was $96 \%$ and $97 \%$, respectively, for $\mathrm{S}$ and $\mathrm{M}$ samples, for fluorescent staining (FS) technique. With two-sample two-smear approach, for ZN staining, SPT was $89 \%$ each and for FS technique, SPT was $97 \%$ and $99 \%$, respectively, for $\mathrm{SS}_{2}$ and $\mathrm{SM}$ approaches. The difference was not statistically significant $(P>0.05)$ between one- and two-sample approaches in the staining techniques.

CONCLUSION: Significant number of SP cases are identified by S sample two-smear approach. Thus, the World Health Organization/Revised National Tuberculosis Control Programme can initiate $\mathrm{S}$ sample two-smear approach for the diagnosis of PT.

Key words:

Sample, Staining, Tuberculosis

\section{Introduction}

$\neg \neg$ uberculosis (TB) is more prevalent 1 among poor people of low living standards. ${ }^{[1,2,3]}$ India has the highest TB burden in the world. ${ }^{[4]}$ In resource-limited countries such as India, rapid diagnostic tests for TB are not possible owing to their high cost. ${ }^{[5]}$ Sputum smear examination (SSE) is the only alternative. ${ }^{[3,6]}$ For SSE, three sputum samples are collected by spot morning spot (SMS) approach. The majority of smear positive (SP) TB cases were however identified in the first two samples. ${ }^{[7]}$ The World Health Organization (WHO) and

This is an open access article distributed under the terms of the Creative Commons Attribution-NonCommercial-ShareAlike 3.0 License, which allows others to remix, tweak, and build upon the work non-commercially, as long as the author is credited and the new creations are licensed under the identical terms.

For reprints contact: reprints@medknow.com
Revised National Tuberculosis Control Programme (RNTCP) therefore reduced the minimum number of samples to two, that is, spot morning $(\mathrm{SM})$ approach. ${ }^{[8]}$

Even with the SM approach, patients were required to visit the health-care center a minimum of two times, which led to patient dropouts (PDs), and $50 \%$ of patients failed to return to provide a second sample or obtain their results. ${ }^{[9,10]}$ However, studies have proved that the diagnostic accuracy of the same-day $\left(\mathrm{SS}_{2}\right)$ approach is on par with the SM approach. ${ }^{[6,11,12]}$ In the $\mathrm{SS}_{2}$ approach, two sputum samples are collected with a gap of $1 \mathrm{~h}$.

How to cite this article: Chandra TJ. One-sample two-smear versus two-sample two-smear approach for the diagnosis of pulmonary tuberculosis. J Lab Physicians 2018;10:135-9. 
The $\mathrm{SS}_{2}$ approach has many advantages: early initiation of treatment, no PDs, and same-day screening of smear-negative (SN) cases with GeneXpert. Due to less bacillary load compared to morning (M) samples, most of the clinicians are reluctant to rely on spot (S) sample results. ${ }^{[13]}$ Another important issue with the $\mathrm{SS}_{2}$ approach is the transmission of TB in the healthcare center as patients need to wait in the microscopy centers for a long time to collect the results. The WHO has responded to this issue in speedup management by providing separate waiting halls as well as face masks. ${ }^{[14,15]}$ However, in high TB burden countries such as India, especially under field conditions, providing waiting halls and face masks is yet another hurdle. In addition to these, continuous motivation of patients for collection of two good-quality $\mathrm{S}$ samples is a significant hurdle in the $\mathrm{SS}_{2}$ approach. The change to the $\mathrm{SS}_{2}$ approach under field conditions therefore remains questionable. The current study was therefore done to determine the diagnostic utility of one sputum sample versus two samples, that is, $\mathrm{SS}_{2}$ and $\mathrm{SM}$ approaches.

To stain acid-fast bacilli in sputum smears, different staining techniques were reported in the literature, Ziehl-Neelsen (ZN) staining, ${ }^{\left[{ }^{[6]}\right.}$ modified ZN staining, ${ }^{[12]}$ reverse $\mathrm{ZN}$ staining, ${ }^{[16]} \mathrm{ZN}$ staining with jar method, ${ }^{[17]}$ and fluorescent staining (FS). ${ }^{[1]}$ However, most of the TB control programes recommend $\mathrm{ZN}$ staining and FS techniques. Hence, in this study also ZN staining and FS techniques were used to stain the sputum smears.

\section{Materials and Methods}

The study was conducted in the Department of Microbiology, GSL Medical College, Rajahmundry, Andhra Pradesh, India, from January 2012 to December 2015. The study protocol was approved by the Institutional Research and Ethics Committee of GSL Medical College.

Individuals with signs and symptoms suggestive of TB were included in the study. The participants were informed to submit deeply coughed sputum sample, minimum $5 \mathrm{ml}$. How to produce good quality of sputum sample was explained in vernacular language, and it was demonstrated practically. Three sputum samples were collected from each patient. After collection of $\mathrm{S}$ and second spot $\left(\mathrm{S}_{2}\right)$ samples, the participants were provided with prelabeled sample containers to collect $\mathrm{M}$ samples on next day, early in the morning, after getting up from bed. Immediately after collection, two smears were prepared and stained by $\mathrm{ZN}$ staining and FS techniques, respectively. Procedure for collection of sputum samples, smear preparation, staining, screening under a microscope, grading of $\mathrm{SP}$ cases were done as per the RNTCP guidelines. ${ }^{[8,18]}$ As a part of internal quality control and study protocol, all the positive smears and randomly $25 \%$ negative smears were rechecked.

Using ZN staining and FS techniques, the data were analyzed as follows:

1. Number of SPs by S sample with one and two smears,

2. Number of SPs by M sample with one and two smears,

3. Number of SPs by two samples with two smears, that is, $\mathrm{SS}_{2}$ and $\mathrm{SM}$ approaches.

\section{Statistical analysis}

Data were analyzed using SPSS, version 16 (SPSS, Inc., Chicago, IL, USA), with patient as the unit of analysis; Chi-square test was used to find the statistical difference in the SP cases between the approaches, staining techniques and the smears. $P<0.05$ was considered statistically significant.

\section{Results}

Of the 2799 participants, $182(6.5 \%)$ did not submit the M sample. Hence, the data were analyzed with 2617 participants. The male:female ratio was 1.32:1. Among the study patients, 232 (100\%) were identified as SP for TB. In the SP cases, the male:female ratio was 1.4:1 and mean age was 34.7 years.

With one-sample one-smear approach, for ZN staining, the smear positivity (SPT) was 80\% (185) each, and for FS technique, the SPT was 89\% (206) and 90\% (208), respectively, for $\mathrm{S}$ and $\mathrm{M}$ samples as shown in Table 1. There was no statistical difference $(P>0.05)$. In this approach, with ZN staining 21 and 23 SP cases were missed for $S$ and $M$ samples, respectively, when compared with the results using FS technique. When compared with the total SPT, in this approach, ZN staining technique missed $47 \mathrm{SP}$ cases each and with FS technique, 26 and 24 SP cases were missed, respectively, for $\mathrm{S}$ and $\mathrm{M}$ samples.

With one-sample two-smear approach, for ZN staining, the SPT was $87 \%$ (202) and $87.5 \%$ (203) and for FS technique, 96\% (223) and 97\% (225), respectively, for $\mathrm{S}$ and $\mathrm{M}$ samples [Table 1]. Statistically, the difference was not significant $(P>0.05)$. In this approach, with $\mathrm{ZN}$ staining technique, 21 and $22 \mathrm{SP}$ cases were missed, respectively, for $\mathrm{S}$ and $\mathrm{M}$ samples when compared with the results using FS technique. In one-sample approach, with two smears in comparison with a single smear, 17 and 18 more SP cases were detected with ZN staining and 17 more SP cases each were detect with FS technique for $\mathrm{S}$ and $\mathrm{M}$ samples, respectively. When compared with the total SPT, in this approach, ZN staining technique missed 30 and 29 SP cases and with FS technique, 9 and 7 SP cases were missed, respectively, for $S$ and $M$ samples. 
Table 1: Findings of smear positives using Ziehl-Neelsen and fluorescent staining in one and two sputum sample and one and two smear approaches

\begin{tabular}{|c|c|c|c|c|c|c|}
\hline & \multicolumn{4}{|c|}{ One sample, $n(\%)$} & \multicolumn{2}{|c|}{ Two sample, $n(\%)$} \\
\hline & \multicolumn{2}{|c|}{ One smear } & \multicolumn{2}{|c|}{ Two smear } & \multirow[t]{2}{*}{$\mathrm{SS}_{2}$ approach } & \multirow[t]{2}{*}{ SM approach } \\
\hline & S sample & M sample & S sample & M sample & & \\
\hline ZN staining & $185(80)$ & $185(80)$ & $202(87)$ & $203(87.5)$ & $206(89)$ & $206(89)$ \\
\hline FS & 206 (89) & 208 (90) & $223(96)$ & 225 (97) & 226 (97.4) & 230 (99) \\
\hline
\end{tabular}

$\mathrm{SS}_{2}=$ Same-day, ZN = Ziehl-Neelsen, SM = Spot morning, FS = Fluorescent staining

With two-sample two-smear approach using ZN staining, the SPT was $89 \%$ (206) each whereas with FS technique, the SPT was $97.4 \%$ (226) and 99\% (230), respectively, for $\mathrm{SS}_{2}$ and SM approaches as shown in Table 1. Statistically, the difference was not significant $(P>0.05)$. In this approach, with ZN staining technique, 20 and $24 \mathrm{SP}$ cases were missed, respectively, for $\mathrm{SS}_{2}$ and $\mathrm{SM}$ approaches when compared with the results using FS technique. When this approach was compared with total SPT, ZN staining technique missed 26 each and FS technique missed 6 and 2 SP cases, respectively, for $\mathrm{SS}_{2}$ and SM approaches.

\section{Discussion}

TB ranks as the second leading cause of death from an infectious disease worldwide, after HIV.${ }^{[19]}$ In addition to gender difference, ${ }^{[20-22]}$ technique used to collect the sputum, that is, intervention, ${ }^{[23]}$ quality and quantity of sputum, ${ }^{[24]}$ type of staining technique, ${ }^{[12,25,26]}$ and number of samples ${ }^{[27]}$ submitted for diagnosis influence the sputum microscopy results. The SPT increase when multiple samples are screened..$^{[28]}$

In this study, 182 participants did not submit the $\mathrm{M}$ sample, so PD was $6.3 \%$. In our previous studies, PD was reported to be $6.3 \%,{ }^{[6]} 4.2 \%,{ }^{[12]} 4.3 \% .^{[1,26]}$ Whereas the PD was reported to be $13 \%$ and $52 \%$, respectively, by Chandrasekaran et al.. ${ }^{[29]}$ and Botha et al. ${ }^{[10]}$

The sensitivity of light-emitting diode-fluorescent microscope (LED-FM) is higher compared to $\mathrm{ZN}$ staining in the diagnosis of TB. ${ }^{[30,31]}$ In this study, for one-sample one-smear approach, FS technique identified 9\% (21) and 10\% (23) more SP cases, and for one-sample two-smear approach, 9\% (21) and 9.5\% (22) more SP cases, respectively, for $\mathrm{S}$ and $\mathrm{M}$ samples. In the two-sample approach, FS technique identified 8.6\% (20) and $10.5 \%$ (24) more cases, respectively, for the $\mathrm{SS}_{2}$ and SM approaches. Statistically, the difference was not significant $(P>0.05)$ between the staining techniques neither within the one-sample approach nor between the one- and two-sample approaches.

Freiman and Pinner ${ }^{[32]}$ reported that examination of second smear from the same specimen resulted in $12 \%$ increase in the proportion of SP specimens.
Cattamanchi et al. ${ }^{[33]}$ reported that with $\mathrm{ZN}$ staining technique, the incremental gain in sensitivity was lower at $4 \%$ and $5 \%$, respectively, for $\mathrm{S}$ and $\mathrm{M}$ samples when the second smear was prepared from the same sample. With LED-FM, the incremental gain in sensitivity was $3 \%$ and $6 \%$, respectively, for $\mathrm{S}$ and $\mathrm{M}$ samples. ${ }^{[33]}$ In this study too, when the second smear was examined from the same sputum, the incremental gain in SPT was $7 \%$ (17) and 7.5\% (18) for ZN staining and 7\% (17) each for FS technique, respectively, for $\mathrm{S}$ and $\mathrm{M}$ samples. The difference in incremental gain in SP cases was not statistically significant $(P>0.05)$ in one-sample approach for $\mathrm{S}$ and $\mathrm{M}$ samples, respectively.

When two-smear approaches were considered, in S sample category, with FS technique, $3(1.3 \%)$ and $7(3 \%)$ SP cases were missed and for M sample category $1(0.4 \%)$ and $5(2 \%)$ SP cases were missed, respectively, for $\mathrm{SS}_{2}$ and $\mathrm{SM}$ approaches. With $\mathrm{ZN}$ staining, in S sample category, 4 (2\%) SP cases each were missed and for $\mathrm{M}$ sample category, 3 (1.5\%) $\mathrm{SP}$ cases each were missed, respectively, for $\mathrm{SS}_{2}$ and SM approaches. Statistically, the difference was not significant $(P>0.05)$. Although statistically there was no significant difference among the SP cases in one-sample two-smear versus two-sample two-smear approaches $(P>0.05)$, nondetection of even a single SP TB patient has consequences for the individual patient and for transmission as it has been shown that each individual with active TB can spread the disease to a minimum of $10-12$ per annum. ${ }^{[34]}$

S sample two-smear approach has several advantages: (1) on par SP results, (2) patient need not come on second day, (3) patients need not wait for a long time in the microscopy centres, so reduction in cross infection, (4) reduction in expenditure in the form of sample containers, (5) ease in preparation of two smears, simultaneously. As per the new RNTCP diagnostic algorithm, ${ }^{[35]}$ chest $X$-ray (CXR) and cartridge-based nucleic acid amplification test (CBNAAT) can also be considered for the diagnosis of TB. Hence, with $\mathrm{S}$ sample two-smear approach, $\mathrm{SN}$ patients can complete the diagnostic algorithm (CXR and CBNAAT) on the same day. Hence, the WHO/RNTCP can initiate $S$ sample two-smear approach with FS technique for the diagnosis of TB. 
Bacillary load was found to be more in the $M$ sample. ${ }^{[12]}$ Hence, with FS technique, $25 \% \mathrm{M}$ samples showed $3+$ grading and $20 \%$ showed scanty result, whereas with S sample, 16\% showed 3+ grading and 24\% showed scanty result. Hence, with the technical point of view, ease in smear reading as well as monitoring the patient response to the treatment are the only advantages with M samples. In addition, if SP patient is graded as 3+, he/she can be educated thoroughly, so that extracare will be taken to control the spread of TB. However, the smear grading has no role to initiate anti-TB treatment (ATT); SPT is the only criteria to initiate ATT.

If bacillary load is high in sputum, technically that may be easy to screen the smears under a microscope; this may be the drawback with the $S$ samples. High cost is the drawback of FS technique. In India, FS is done at free of cost because, RNTCP in partnership with the International Union Against TB and Lung Disease, ZN staining was replaced by FS technique and LED FMs were installed ${ }^{[31]}$ in all the Medical Colleges. However, the number of SP cases which were missed are also very important criteria. In S sample two-smear approach, with FS technique, 9 (3.9\%) SP cases were missed when compared to the total SPT. As per Chandra, ${ }^{[6]}$ ethically we should not miss even a single SP case of TB. However, this number can be considered when compared with the PDs, which were reported to be much more especially in the field conditions. ${ }^{[29]}$

\section{Conclusion}

Significant number of SP cases are identified by S sample two smear approach. Thus, the World Health Organization/Revised National Tuberculosis Control Programme can initiate $\mathrm{S}$ sample two smear approach for the diagnosis of PT. However, a study in the field conditions in high TB burden countries is recommended.

\section{Financial support and sponsorship}

Nil.

\section{Conflicts of interest}

There are no conflicts of interest.

\section{References}

1. Chandra TJ. Phd Thesis. Saveetha University; 1 December, 2016.

2. Oxlade O, Murray M. Tuberculosis and poverty: Why are the poor at greater risk in India? PLoS One 2012;7:e47533.

3. Chandra TJ. Correlation between serum calcium levels and smear grading among the pulmonary tuberculosis patients. J Microbiol Infect Dis 2018;8:19-22.

4. Sachdeva KS, Kumar A, Dewan P, Kumar A, Satyanarayana S. New vision for Revised National Tuberculosis Control Programme (RNTCP): Universal access - "Reaching the un-reached". Indian J Med Res 2012;135:690-4.

5. Chandra TJ, Selvaraj R, Sharma YV. Comparison of variants of carbol fuchsin \& phenol in Ziehl Neelsen staining to detect AFB J Mycobacteriol Dis 2012;3:131.

6. Chandra TJ. Same day sputum smear microscopy approach for the diagnosis of pulmonary tuberculosis in a microscopy centre at Rajahmundry. Indian J Tuberc 2012;59:141-4.

7. Bonnet M, Ramsay A, Gagnidze L, Githui W, Guerin PJ, Varaine F, et al. Reducing the number of sputum samples examined and thresholds for positivity: An opportunity to optimise smear microscopy. Int J Tuberc Lung Dis 2007;11:953-8.

8. Central TB Division, Directorate General of Health Services Ministry of Health and Family Welfare. Manual for Sputum Smear Fluorescence Microscopy. New Delhi, India: Ministry of Health and Family Welfare. Available from: http://www.tbcindia.nic in/showfile.php?lid=2988. [Last accessed on 2015 Dec 26].

9. Squire SB, Belaye AK, Kashoti A, Salaniponi FM, Mundy CJ, Theobald $\mathrm{S}$, et al. 'Lost' smear-positive pulmonary tuberculosis cases: Where are they and why did we lose them? Int J Tuberc Lung Dis 2005;9:25-31.

10. Botha E, den Boon S, Lawrence KA, Reuter H, Verver S, Lombard CJ, et al. From suspect to patient: Tuberculosis diagnosis and treatment initiation in health facilities in South Africa. Int J Tuberc Lung Dis 2008;12:936-41.

11. Chandra TJ, Raj RS, Sharma YV. Same day sputum smear microscopy for the diagnosis of pulmonary tuberculosis: Direct versus concentrated sputum smear. Int J Tuberc Lung Dis 2015;20:247-51.

12. Chandra TJ, Raj RS, Sharma YV. Same day sputum smear microscopy approach with modified ZN staining for the diagnosis of pulmonary tuberculosis in a microscopy centre at Rajahmundry. Indian J Med Microbiol 2014;32:153-6.

13. Cuevas LE, Al-Sonboli N, Lawson L, Yassin MA, Arbide I, Al-Aghbari $\mathrm{N}$, et al. LED fluorescence microscopy for the diagnosis of pulmonary tuberculosis: A multi-country cross-sectional evaluation. PLoS Med 2011;8:e1001057.

14. World Health Organization. Addendum to WHO Guidelines for the Prevention of Tuberculosis in Health Care Facilities in Resource-Limited Settings, 1999. Tuberculosis Infection Control in the Era of Expanding HIV Care and Treatment. Geneva, Switzerland: WHO; 2006.

15. Dharmadhikari AS, Mphahlele M, Stoltz A, Venter K, Mathebula R, Masotla T, et al. Surgical face masks worn by patients with multidrug-resistant tuberculosis: Impact on infectivity of air on a hospital ward. Am J Respir Crit Care Med 2012;185:1104-9.

16. Chandra TJ, Senthil S, Selvaraj R, Sharma YV. Same day sputum smear microscopy: ZN staining versus RZN staining. J Pure Appl Microbiol 2016;10:1599-602.

17. Chandra TJ, Selvaraj R, Sharma YV. Same day sputum smear microscopy with an economical destaining step for the diagnosis of pulmonary tuberculosis. J Clin Sci Res 2015;4:244-7.

18. RNTCP Central TB Division, Directorate General of Health Services. Manual for Laboratory Technicians. New Delhi, India: Directorate General of Health Services, Ministry of Health and Family Welfare; 1998.

19. World Health Organization. The Global Plan to Stop TB, 2011-2015. WHO/HTM/STB/2010.2. Geneva, Switzerland: WHO; 2010.

20. Boum $Y 2^{\text {nd }}$, Atwine D, Orikiriza P, Assimwe J, Page AL, Mwanga-Amumpaire J, et al. Male gender is independently associated with pulmonary tuberculosis among sputum and non-sputum producers people with presumptive tuberculosis in Southwestern Uganda. BMC Infect Dis 2014;14:638.

21. Neyrolles O, Quintana-Murci L. Sexual inequality in tuberculosis. PLoS Med 2009;6:e1000199.

22. Khan MS, Dar O, Sismanidis C, Shah K, Godfrey-Faussett P. Improvement of tuberculosis case detection and reduction of discrepancies between men and women by simple sputum-submission instructions: A pragmatic randomised 
controlled trial. Lancet 2007;369:1955-60.

23. Chandra TJ, Rao PA, Srinivas G, Moorthy NV, Rao PV. Role of fiberoptic bronchoscopy in smear negative and suspect cases of pulmonary tuberculosis. NTI Bull 2006;42:12-4.

24. Ramsay A, Bonnet M, Gagnidze L, Githui W, Varaine F, Guérin PJ, et al. Sputum, sex and scanty smears: New case definition may reduce sex disparities in smear-positive tuberculosis. Int J Tuberc Lung Dis 2009;13:613-9.

25. Chandra TJ, Selvaraj R, Allam RR, Sharma YV. Same day sputum smear microscopy for the diagnosis of pulmonary tuberculosis: Modified ZN staining versus LED FM. Int J Curr Microbiol App Sci 2015;4:75-81.

26. Chandra TJ, Selvaraj R, Sharma YV. Same day sputum smear microscopy for the diagnosis of pulmonary tuberculosis: Ziehl-Neelsen versus fluorescent staining. J Family Med Prim Care 2015;4:525-8.

27. Nelson SM, Deike MA, Cartwright CP. Value of examining multiple sputum specimens in the diagnosis of pulmonary tuberculosis. J Clin Microbiol 1998;36:467-9.

28. Rao KR. Inter and intra-reader variations in direct microscopy and their influence on sensitivity and specificity. Proceedings of the $24^{\text {th }}$ National TB \& Chest Disease Workers Conference. Trivandrum, India; 1969. p. 99-110.
29. Chandrasekaran V, Ramachandran R, Cunningham J, Balasubramaniun R, Thomas A. Factors leading to tuberculosis diagnostic dropout and delayed treatment initiation in Chennai, India. Int J Tuberc Lung Dis 2005; 9: 172.

30. Reza LW, Satyanarayna S, Enarson DA, Kumar AM, Sagili K, Kumar S, et al. LED-fluorescence microscopy for diagnosis of pulmonary tuberculosis under programmatic conditions in India. PLoS One 2013;8:e75566.

31. Bhalla M, Sidiq Z, Sharma PP, Singhal R, Myneedu VP, Sarin R. Performance of light emitting diode fluorescence microscope for the diagnosis of tuberculosis. Int J Mycobacteriol 2013;2:174-8.

32. Freiman DG, Pinner M. Routine examination of sputum for acid-fast bacilli. Am Rev Tuberc 1949;59:449-60.

33. Cattamanchi A, Huang L, Worodria W, den Boon S, Kalema N, Katagira $W$, et al. Integrated strategies to optimize sputum smear microscopy: A prospective observational study. Am J Respir Crit Care Med 2011;183:547-51.

34. WHO. 2007 Annual Report. Available from: http://www. who.int/entity/whr/2007/whr07en.pdf. [Last accessed on 2016 Dec 07].

35. RNTCP 2016. Available from: http://www.tbcindia.gov.in/ index1.php?lang $=1 \&$ level $=2 \&$ sublinkid $=4573 \&$ lid $=3177$. [Last accessed on 2017 Jun 17]. 